\title{
APLICAÇÃO DO AÇO NA CONSTRUÇÃO CIVIL NA PLANTA DA ARCELORMITTAL TUBARÃO - PRINCIPAIS VANTAGENS EM RELAÇÃO AO CONCRETO ARMADO*
}

Fernanda Simões Ribeiro Curcio ${ }^{1}$ Luiz Claudio Thiebaut Pereira ${ }^{2}$ Salustiano Pinto ${ }^{3}$

\section{Resumo}

Durante muitos anos, diversas edificações na planta da ArcelorMittal Tubarão, tais como: unidades fabris, vestiários, canteiros e refeitórios, foram construídas utilizando concreto armado. Aplicar o aço na construção civil e, desta forma, fomentar o uso do aço nesta área, sempre foi uma grande vontade da empresa. Nos últimos anos, esse interesse tem se tornado realidade, tendo sido adquiridas edificações construídas com sistema Light Steel Framing e outras estruturadas em perfis laminados. Além de impulsionar o consumo do aço, essas unidades apresentaram diversas vantagens em relação à construção em concreto armado, como: redução no custo de implantação, melhor controle do cronograma de execução, abatimento no prazo para execução dos serviços e menor exposição dos trabalhadores aos riscos operacionais, já que apenas as interligações das utilidades foram executadas no local. As primeiras unidades adquiridas tem apresentado excelente desempenho ao longo do tempo, mesmo considerando o ambiente industrial e marinho ao qual a planta da ArcelorMittal Tubarão está submetida.

Palavras-chave: Light Steel Framing; Construção Modular; Segurança; Redução de Custos.

\section{APPLICATION OF STEEL IN BUILDINGS IN ARCELORMITTAL TUBARÃO - MAIN ADVANTAGES IN RELATION REINFORCED CONCRETE}

\section{Abstract}

For many years, several buildings in the ArcelorMittal Tubarão, such as: manufacturing units, locker rooms and dining rooms, were built using reinforced concrete. Applying steel in civil construction and, thus, promoting the use of steel in this area, has always been a great desire of the company. In the last years, this interest has become reality, having been acquired buildings constructed with Light Steel Framing system and others structured in rolled profiles. In addition to boosting the consumption of steel, these units presented several advantages in relation to the construction of reinforced concrete, such as: cost reduction, better control of the schedule, reduction in the deadline for execution of services and less exposure of workers to risks. Only utilities interconnections were carried out on site. The first units acquired have shown excellent performance over time, even considering the industrial and marine environment to which the ArcelorMittal Tubarão plant is subjected.

Keywords: Light Steel Framing; Modular Construction; Safety; Cost Reduction.

1 Engenharia Civil, Mestre, Especialista em Engenharia Civil/ Área de Engenharia de Manutenção Mecânica, ArcelorMittal Tubarão, Serra, Espírito Santo, Brasil.

2 Engenharia Elétrica, Coordenador de Projetos, Departamento de Projetos e Engenharia, ArcelorMittal Tubarão, Serra, Espírito Santo, Brasil.

3 Engenharia Mecânica, Mestre, Coordenador de Projetos, Departamento de Projetos e Engenharia, ArcelorMittal Tubarão, Serra, Espírito Santo, Brasil. 


\section{INTRODUÇÃO}

O aço é um material amplamente empregado na construção civil em diversos países da Europa e nos Estados Unidos da América, mas ainda pouco aplicado no Brasil. No mercado europeu, principalmente na Inglaterra, bem como nos Estados Unidos, o consumo de aço para construção civil gira em torno de $100 \mathrm{~kg}$ per capta ao ano, enquanto no Brasil não chega a $12 \mathrm{~kg}$. Essa limitação no emprego do aço na construção civil brasileira deve-se, principalmente, a questões culturais e de qualificação de mão-de-obra.

O uso do aço na construção civil apresenta diversas vantagens em relação ao concreto armado. A estrutura em aço é mais leve e, com isso, reduz as cargas nas fundações. Por se tratar de um material fabricado em indústrias, reduz o desperdício e permite a execução de projetos variados e arrojados. Para a maioria dos clientes, a principal vantagem das estruturas de aço, é a rapidez, quando comparada com a construção convencional, na qual em obras com o cronograma bem elaborado conseguem reduzir o tempo de execução em até $40 \%$.

Considerando todas essas vantagens, e interessados em ampliar o consumo de aço, a ArcelorMittal Tubarão iniciou um processo de avaliação de viabilidade para implantação de edificações estruturadas em aço. Além das vantagens supracitadas, foi verificado que, para implantação dentro da planta, o custo das edificações préfabricadas em aço era inferior as construídas em concreto armado.

\section{MATERIAIS E MÉTODOS}

Os materiais utilizados nas unidades modulares adquiridas estão descritas nos subitens a seguir. Os materiais variam de acordo com a finalidade dos módulos.

\subsection{Salas para escritório}

As primeiras unidades modulares foram adquiridas pela ArcelorMittal Tubarão em 2011. Cada unidade tinha área de $14,80 \mathrm{~m}^{2}$ e apresentavam as seguintes características:

- Estruturas de sustentação em perfis laminados;

- Fechamento em placas de poliuretano, com 40mm espessura, acabadas com chapas de aço galvanizado pintadas com espessura de $0,5 \mathrm{~mm}$;

- Rebaixamento de teto em placas de fibra mineral;

- Revestimento de piso com manta vinílica em PVC para alto tráfego.

\subsection{Vestiários}

Quando o Refeitório da Aciaria Sul foi reformado, foi necessário construir um novo vestiário para atender aos funcionários do refeitório e, após ampla análise das opções oferecidas pelo mercado, optou-se por utilizar o conceito "Light Steel Framing". Trata-se de um sistema estruturado por perfis galvanizados conformados a frio que permite que tubulações e eletrodutos fiquem embutidos e oferecem flexibilidade no projeto.

A área total foi de $33 \mathrm{~m}^{2}$ e os materiais aplicados foram:

- Estruturas em aço galvanizado conformado a frio e perfis laminados (Figura $1)$; 
- Fechamento externo em painéis OSB Home Plus e interno em placas cimentícias, revestidas com cerâmica (Figura 2);

- Rebaixamento de teto em placas de PVC;

- Revestimento de piso com cerâmica PEI5.

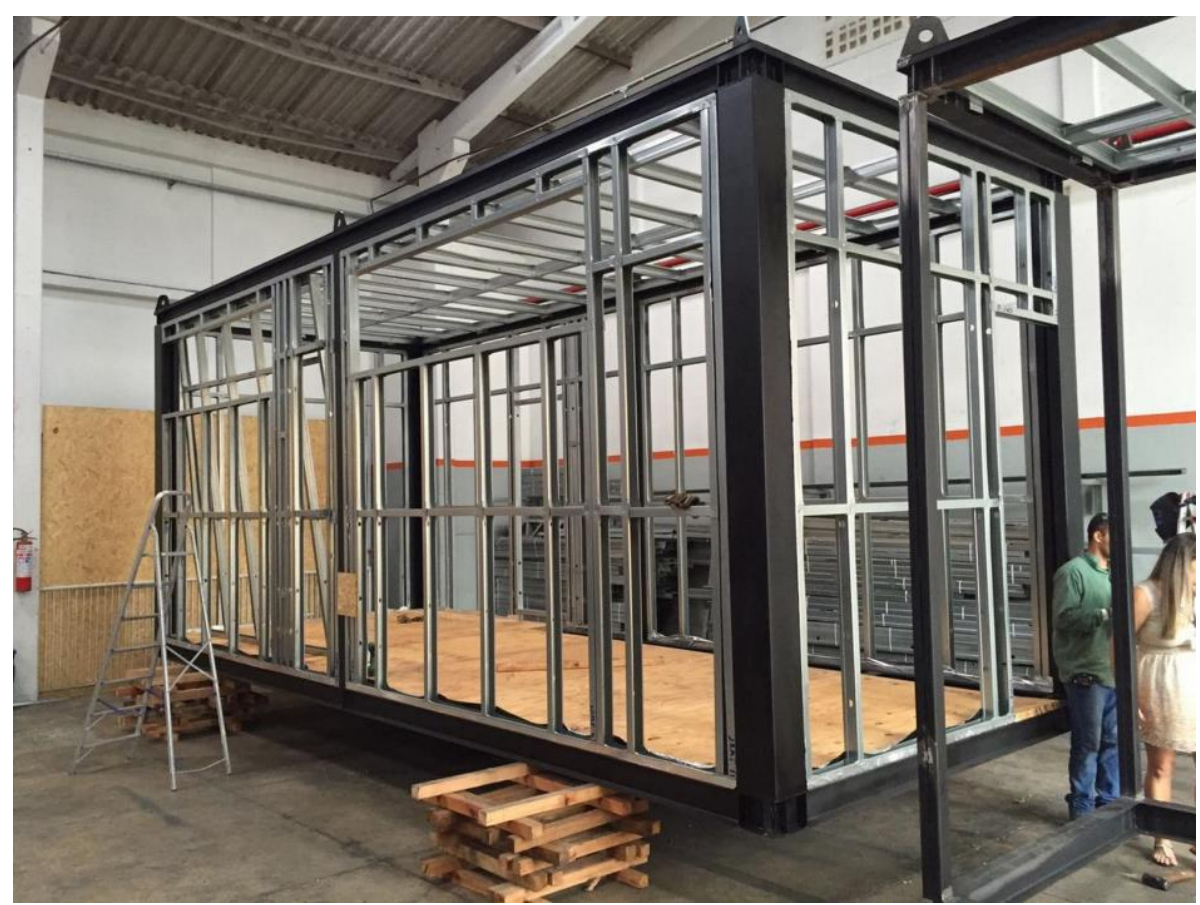

Figura 1. Estrutura em aço do vestiário.

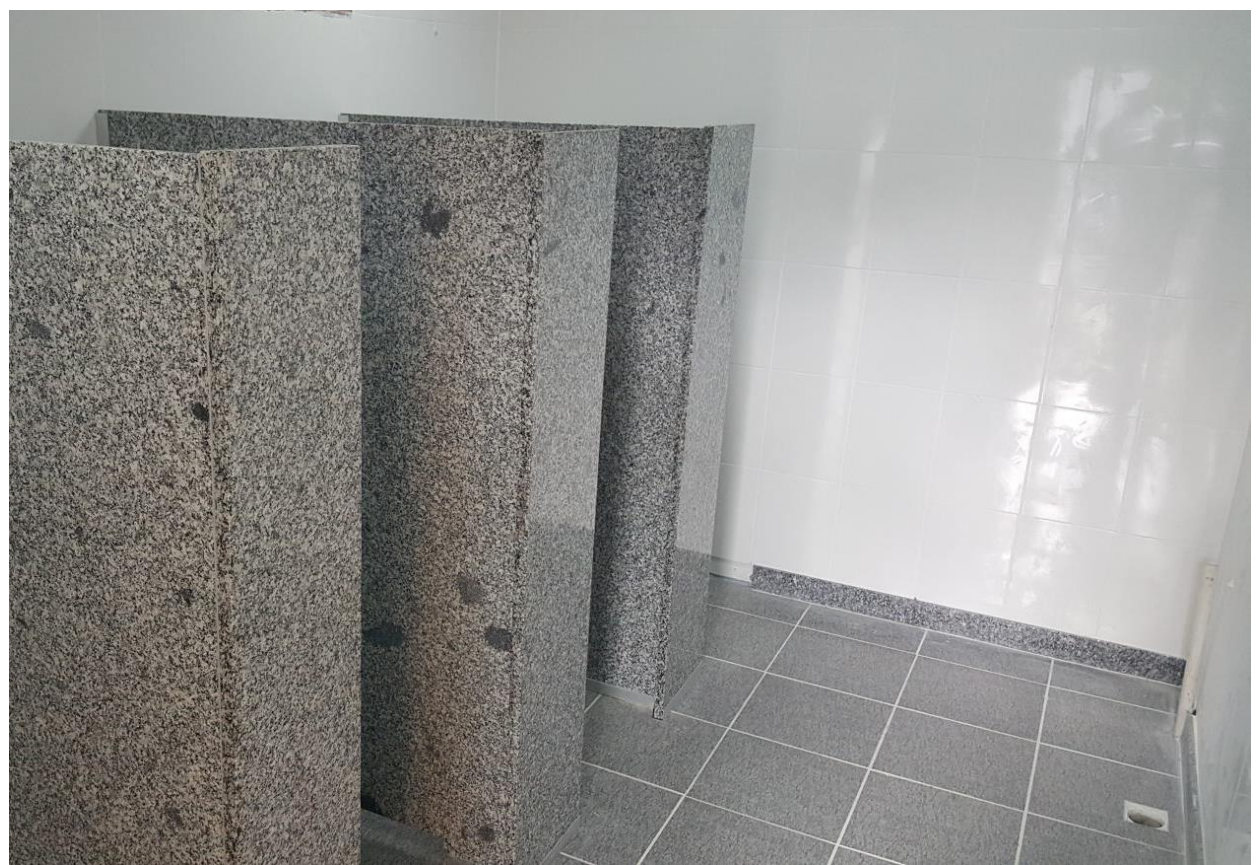

Figura 2. Acabamento interno do vestiário.

\subsection{Unidade fabril}

A unidade fabril adquirida para atendimento a equipes de manutenção tem $183,82 \mathrm{~m}^{2}$ (Figura 3) e foram utilizados os materiais: 
- Estruturas de sustentação em perfis laminados;

- Fechamento em placas de poliuretano, com 40mm espessura, acabadas com chapas de aço galvanizado pintadas com espessura de $0,5 \mathrm{~mm}$;

- Rebaixamento de teto em placas de fibra mineral;

- Revestimento de piso com manta vinílica em PVC para alto tráfego para áreas secas e revestimento cerâmico para áreas molhadas (banheiro e copas).

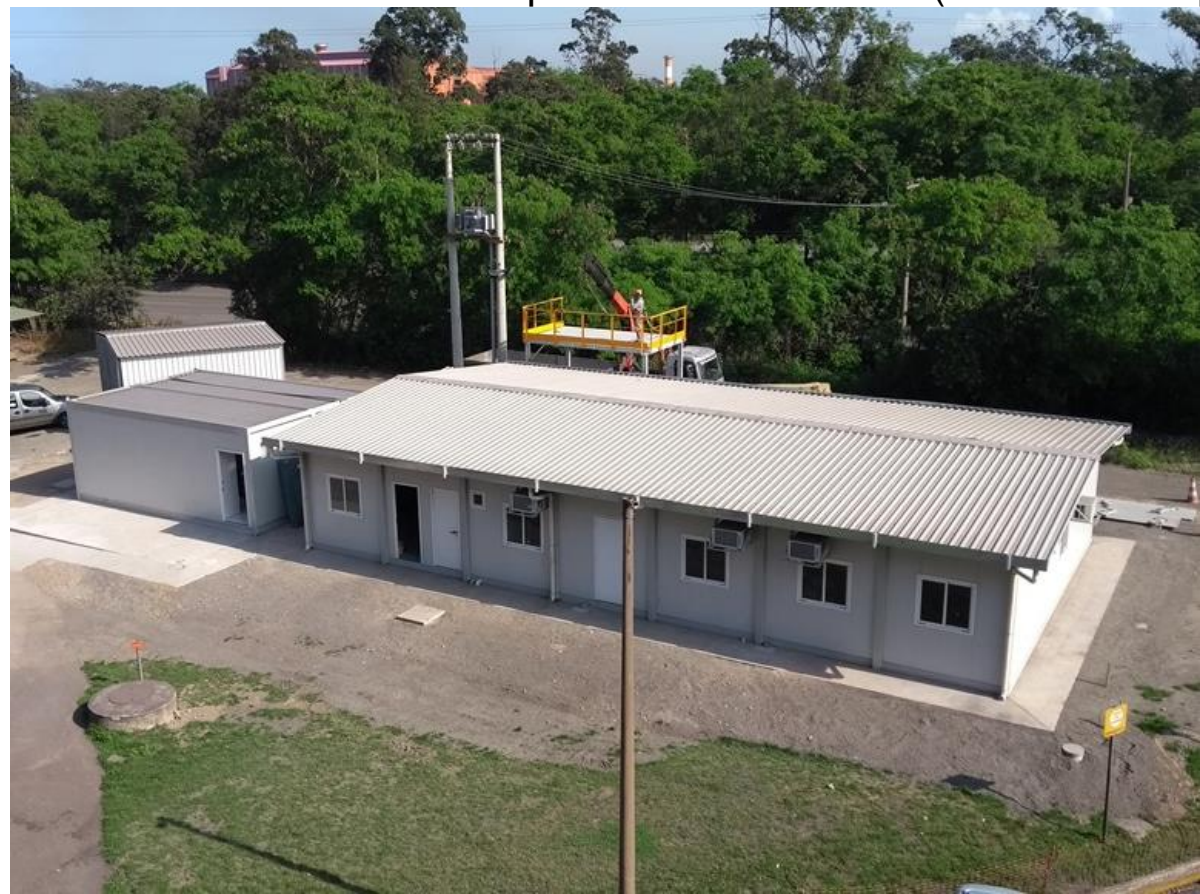

Figura 3. Visão geral da unidade modular para escritório fabril.

\section{RESULTADOS E DISCUSSÃO}

As construções estruturadas em aço adquiridas pela ArcelorMittal Tubarão apresentaram custo inferior ao método convencional. A redução de custo variou entre $6,5 \%$ e $40 \%$, quando comparado com construções com estruturas em concreto armado.

Em todos os casos citados, houve redução no prazo para implantação do projeto e no número de operários atuando na execução dos serviços, reduzindo assim a exposição de pessoas aos riscos operacionais, já que se trata de uma usina siderúrgica. Além disso, o uso de construção pré-fabricada possibilitou um melhor controle do cronograma de implantação do projeto e redução no custo de fiscalização e gerenciamento.

\section{CONCLUSÃO}

A ArcelorMittal é o maior fabricante de aço no mundo. Estimular o consumo do aço nas mais diversas áreas sempre foi um grande interesse do grupo, especialmente da planta de Tubarão. Assim, vencer os paradigmas e adquirir unidades estruturadas em aço foi um grande avanço para empresa. O resultado desta experiência foi amplamente satisfatório, gerando cada vez mais interesse no uso do aço para novas edificações.

As primeiras unidades instaladas na planta da ArcelorMittal Tubarão apresentam perfeito estado de conservação, mesmo com ambiente industrial e marinho ao qual a 
planta está submetida. Ou seja, com tratamento adequado do aço empregado, a vida útil do sistema supera as expectativas do projeto. Outro ponto positivo foi o conforto térmico observado nestas unidades. Tanto a vedação com poliuretano revestido com chapas metálicas, quando placas em OSB e cimentícia (com colchão de ar entre eles) conferem um isolamento térmico e acústico muito mais eficiente que a alvenaria em lajotas com espessura de $90 \mathrm{~mm}$.

\section{REFERÊNCIAS}

1 A hora e a vez do aço na Construção Civil. Grandes Construções. 2011 [acesso em 18 jun. 2017];: Disponível em:

http://www.grandesconstrucoes.com.br/br/index.php?option=com conteudo\&task=view Materia\&id=506 